\title{
O HOMEM NO PENSAMENTO DE DUNS SCOTUS: ASPECTOS CARACTERISTICOS DE SUA ANTROPOLOGIA
}

\author{
Luis Alberto De Boni*
}

\begin{abstract}
SINTESE - Em seus tratados teológicos, os pensadores medievais defrontaram-se com a pergunta a respeito do homem, como ser criado, como capaz de conhecer, de praticar o bem ou o mal etc. e, com isto, elaboraram uma Antropologia. Dentre eles, Duns Scotus, mantendo-se fiel a certos temas caros à escola franciscana, caracteriza-se por haver seguido caminhos surpreendentemente novos. No presente texto, dois aspectos da Antropologia scotista são estudados. Em primeiro lugar, a noção de matéria e forma. Discordando da teoria aristotélico-tomista, ele acentua a realidade especifica da matéria, cuja existência, sem a forma, não pode resumir-se à pura potencialidade. Redefinindo o que é a matéria, ele redefine também as relaçōes entre alma e corpo. Em segundo lugar, e reservando bem maior espaço, a questão da vontade como potência livre, que se determina a si mesma.

PALAVRAS-CHAVE - Antropologia. Duns Scotus. Matéria e forma. Necessidade. Contingência. Liberdade.
\end{abstract}

\begin{abstract}
In their theological treatises, medieval thinkers faced the question of man Qua created being, capable of knowing, doing good or evil, and so forth, hence their anthropology. Among them, Duns Scotus is characterized for having taken surprisingly new ways, even though the remained faithful to certain themes cherished by the Franciscan school. This text focus on two aspects of Scotist anthropology. First, it deals with the notions of matter and form, in disagreement with the Aristotelian-Thomist theory, so as to stress the specific reality of matter, whose existence without form cannot be reduce to pure potentiality. By redefining what matter is, it also redefines the body-soul relations. Secondly, it deals extensively with the questions of the will Qua free potency which determines itself.

KEY WORDS - Anthropology. Duns Scotus. Matter and form. Necessity. Contingency. Freedom.
\end{abstract}

Há verdades histórico-filosóficas que, na linguagem clássica, poderiam ser classificadas como "evidentes por si mesmas". Sem dúvida, Avicena, para quem as negasse, haveria de sugerir seu único argumento a respeito: o uso do chicote, alegando que não está sendo usado. Em se tratando de Filosofias medievais, não são somente os leigos que fazem julgamentos precipitados; também alguns acadêmicos atrapalham-se, mesmo em se tratando de evidências. De fato, nada mais fácil do que olhar de longe para um periodo histórico-filosófico e proferir a respeito dele juízos globalizantes, cujo pressuposto não expresso, e mesmo inconsciente, é

* Pontifícia Universidade Católica do Rio Grande do Sul - PUCRS.

\begin{tabular}{|l|l|l|l|l|l|}
\hline VERITAS & Porto Alegre & v. 44 & n. 3 & Setembro 1999 & p. 707-726 \\
\hline
\end{tabular}


o de que à noite todas as vacas são pretas e todos os gatos são pardos. Ora, já há quase um século, F. Picavet, do alto de sua competência - e de seu agnosticismo - observava que não se deveria falar de Filosofia medieval, no singular, mas de Filosofias medievais, ${ }^{1}$ no plural. Com isto, estava apenas constatando o que sempre mais se evidenciou, mas que seguidamente é esquecido: o panorama acadêmico medieval é tão colorido, tão nuanceado, como o de outros períodos, o que torna vazias, quando não falhas, tanto as generalizações como as interpretações redutoras. $\mathrm{Na}$ noite da Idade Média nem todos os gatos são pardos!

Hoje em dia, creio eu, a forma mais desastrosa destes julgamentos não é mais a da prevenção ante a Idade Média, mas a do preconceito a favor de um único autor. Então, nem todos os gatos são pardos, pois há um - e tão somente um - de outro pelo. Modelo de tal preconceito é o que cerca a figura de Tomás de Aquino. A Filosofia medieval é a dele; as outras - citando o argumento fundamentalista talvez possam até ser dispensadas, porque, quando certas, coincidem com a de Tomás e, quando erradas, não é preciso estudá-las. Ainda há pouco, num importante e sob muitos aspectos interessante documento eclesiástico, a encíclica Fides et ratio, quando o tema foi o de uma olhada nos caminhos percorridos pela Filosofia acadêmica que se desenvolveu no Ocidente, constata-se a manutenção do velho esquema cosmológico de manhã, meio-dia e pôr-do-sol. No zênite, às doze horas em ponto, encontra-se Tomás de Aquino. Ele é o doctor communis, cuja doutrina toma-se comum para a Igreja; ele é o metro, pelo qual os demais pensadores são medidos; ele é guardião da fé, por cuja ortodoxia os outros são julgados (na antiga União Soviética, dir-se-ia que ele é o ideólogo oficial do sistema: pensar diferente significa, então, um desvio). Há ele e os outros; a Filosofia dele e a do resto.

Estas colocações não são feitas para abrir um debate sobre as Filosofias medievais, e menos ainda para discutir o grau de importância ou o valor filosófico da obra de um ou outro pensador daquela época. Elas visam tão somente introduzir na temática a ser abordada: a da noção de homem na obra de Duns Scotus. Para quem leu a Antropologia dos manuais de Filosofia escolástica, quase todos ad mentem sancti Thomae, e agora defronta-se com algumas colocações do pensamento scotista a respeito do mesmo problema, não passará despercebido que há discrepâncias não negligenciáveis entre os dois pensadores. $\mathrm{E}$, se for mais a fundo, verá que tais discrepâncias perpassam dois diferentes modos ou, se se quiser, dois diferentes sistemas filosóficos, sistemas esses que não se deixam reduzir um ao outro, como bem observou E. Gilson. ${ }^{2}$ Por isso mesmo, é preciso ler Duns Sco-

Cf. Esquisse d'une histoire générale et comparée des philosophies médiévales (1905); Essais sur I'histoire générale et comparée des théologies et des philosophies médiévales (1913).

2 E. Gilson. Jean Duns Scot. Introduction à ses positions fondamentales. Paris, 1952. p. 650-669. A respeito da posição de B. Gilson, diz W. Kluxen ("On Metaphysics and the Concept of Freedom in the Philosophy of John Duns Scotus". In: E. P. Bos (ed.) John Duns Scotus Renewal of Philosophy. Amsterdam, 1998): "However, the continuing research on Scotus has shown that Gilson was right in his fundamental recognition of Scotus's originality, the coherence of his position, and the alternative to Thomas's ideas: The two conceptions cannot be reduced to each other, they are mutually incompossible. Gilson considered each of the positions as rationally 'possible', but he did not bilieve that a final rational decision of the alternative was possible. An option is required, for wich there are always grounds, but not cogent ones." Esta é também a posição de L. Honnefelder, sinte- 
tus com os olhos de Duns Scotus, a fim de evitar a crítica feita inclusive ao próprio Gilson, de que teria lido Scotus dentro dos parâmetros da Filosofia de Tomás de Aquino. $^{3}$

Isto posto, e a fim de melhor analisar o núcleo da Antropologia scotista, dividirei o presente trabalho em três partes: 1 . A noção de matéria e sua importância para a compreensão da relação entre corpo e alma; 2. Necessitarismo grego e contingência bíblica; 3. A liberdade como noção central da Antropologia scotista.

\section{A noção de matéria e sua importância para a compreensão da relação entre corpo e alma}

Lendo Aristóteles, aceitando a teoria das quatro causas e a da interdependência entre matéria e forma, os medievais eram compelidos a perguntar-se sobre 0 que é matéria e o que é forma. Quanto à primeira, que nos interessa, a 'escola franciscana', desde Boaventura até Ockham, jamais deixou de questionar a solução aristotélico-tomista, por parecer-lhe incapaz de resolver as dificuldades que gerava.

Duns Scotus, aceitando como ponto fundamental, e para ele inquestionável, que não existem intermediários entre o ser e o não-ser, lança-se à tentativa de explicar o que vem a ser a matéria, visto que, a respeito dela, existe a afirmação de que é algo meramente em potência. Mas então, o que é ela? Certamente não é forma em potência, nem composto de matéria e forma em potência, porque então o que estaria em potência seria a forma ou o composto. Mas se for afirmado que ela é matéria em potência, então ainda não existe, pois é somente potência. ${ }^{4}$ Acontece, porém, que nosso conhecimento origina-se a partir dos objetos com os quais nossos sentidos se deparam, e como os sentidos não captam nem a forma pura, nem a matéria sem forma, é necessário um trabalho de elaboração filosófica para compreender o que vem a ser a matéria. Ora, em toda mudança, tanto acidental como substancial, existe um sujeito passivo, sobre o qual acontece a mu-

tizada principalmente em "Der zweite Anfang der Metaphysik. Voraussetzungen, Ansătze und Folgen der Wiederbegründung der Metaphysik im 13./14. Jahrhundert." In: J. P. Beckman et al. (org.). Philosophie im Mittelalter. Hamburg, 1987. p. 165-186.

3 Cfr. C. Bérubé. "Jean Duns Scot. Critique de l'avicennisme augustinisant sur l'objet de l'intelligence"; e "Interprétations virtualisantes de la thèse scotiste de l'objet de l'intellect". In: Id. De l'homme à Dieu selon Duns Scot, Henri de Gand et Olivi. Roma, 1983. p. 113-146; 147-183.

4

"[...] aut est in potentia materia, aut forma aut compositum. Non forma aut compositum in potentia quia non esset materia sed forma aut compositum. Si autem materia, igitur nondum est materia; igitur nihil est sicut prius" (Lect. II, d 12, q un., n 2-3; XIX, 69). Sobre a noção de matéria na escola franciscana cfr. o recente e excelente texto de A. P. Estévez. La materia - de Avicena a la Escuela Franciscana. Maracaibo, 1998 (no que tange à matéria em Duns Scotus, a análise prolonga-se entre as páginas 377 e 431). Cfr. também P. T. Stella. "La teoria llemorfica nel sistema scotista". In: Comissio Scotistica (org.). De doctrina I. Duns Scoti. Acta Congressus Scotistici Intemationalis. Oxonii et Edimburgi. 11-17.10.1966. Roma, 1968, vol. 2. p. 241-295; C. Lértora Mendoza. "Escoto y el hilemorfismo aristotélico". In: Comissio Scotistica (org.). Methodologica ad mentem Joannis Duns Scoti. Atti del Congresso Scotistico Intemazionale. Roma 9-11.03.1993. Roma, 1995. p. 765-781. Quanto à citação das obras de Duns Scotus, se nada for observado, trata-se da editio Vaticana, ainda incompleta. Nos demais casos está apontada a edição Vivès (Paris, 1892-1896). Fazem exceção: o Tractatus de primo principio, citado pela edição Kluxen (Darmstad, 1972) e as Quaestiones in Metaphysicam, pela edição critica recente (St. Bonaventure, 1997). 
dança. Quando acidental, tal sujeito é a substância, que permanece a mesma ao se modificarem os acidentes; quando substancial, é a matéria, que permanece a mesma quando uma forma deixa de existir e começa a existir uma outra. A mudança, portanto, leva-nos a formar uma noção do que seja a matéria, na medida em que a forma simples, por si mesma, não tende à modificação, requerendo-se, pois, um princípio receptor da forma, pelo qual as coisas possam ser e não-ser.

Tal princípio, que é a matéria, está em potência para a forma, não no sentido de que esteja em potência para existir separadamente de sua causa, pois em tal caso tratar-se-ia de um não-ser, mas num segundo sentido, como algo que existe em ato, enquanto subsiste fora de sua causa, mas em potência para ser atuada pela forma, enquanto não possui forma alguma. ${ }^{6}$ A matéria, portanto, possui um ato ínfimo, que lhe confere tão somente o ser, privado de qualquer forma, mas apto a receber todo ato formal. Não fora assim, e o composto seria composto tão somente de forma, ou de forma e nada, o que é a mesma coisa, pois se a matéria não existe por si mesma, separada da forma, então parece que não se pode explicar o que venha a ser a matéria antes de receber a forma.

Mas o ser da matéria, devido à sua imperfeição, não permite que ela seja tomada como uma entidade, no sentido de que o composto resultante de matéria e forma possa ser caracterizado mais como agregado que como composto. Matéria e forma são seres absolutos e distintos, mas, por natureza, existem para serem partes de um outro ser, que é o composto de ambas; a matéria, por natureza, está voltada para receber a perfeição formal, como potência para receber 0 ato. ${ }^{6}$

Se assim é, então a unidade intrínseca da substância composta acontece não pelo predomínio de um de seus componentes sobre o outro (da forma sobre a matéria, na leitura criticada por Scotus), mas pela relação de interdependência e de proporcionalidade entre ambos. Não é a forma que confere o ser à substância e à matéria, pois a matéria possui seu próprio ser e ela, junto com a forma, constituem, juntas, o princípio ontológico único que confere o ser ao composto.

Assim considerada, a matéria é uma substância não determinada e não individualizada, por faltar-lhe a heceidade, proveniente da perfeição formal. Ela não é, pois, uma substância numericamente una e, por isso, não se encontra ao alcance de nossos sentidos, tal como não se encontram as coisas supremas e as ínfimas, ${ }^{7}$ nem pode ser classificada em gênero ou espécie, como havia percebido Aristóteles. ${ }^{8}$ Nem por isso, porém, pode-se negar-lhe a existência enquanto distinta da forma, pois não é da essência da noção de matéria que deva ela ser pensada como unida à forma. A noção de matéria não implica necessariamente a noção de forma. E se é possível que os acidentes possam existir sem o suporte da substância,

5 "Est igitur ens in potentia secundo modo, sicut aliquod ens positivum, quod natum est recipere actum et ens in potentia ad omnes actus quod potest recipere. Et sic est magis ens in potentia quam subiectum accidentis, quia minus in se habens actualitatis et maioris actualitatis capax" (Lect. II, d 12, q un., n 37; XIX, p. 82).

5 "Materia autem est pars entis per se, et intrinseca, et ex natura sua propria, quia receptiva actus et perfectionis, ideo materia et forma faciunt vere unum" (Rep. Par. II, d 12, q 1; Vivès, XXIII, 9).

7 "[...] nec perfectissima in natura et suprema, nec imperfectissima et infima sunt a nobis cognoscibilia pro statu isto, nec proportionata intellectui nostro" (Rep. Par. II, d 12, q 1: XXIII, p. 13).

Aristóteles. VII Metafisica 1029a 20-21. 
como a Teologia afirma a respeito da presença de Cristo na Eucaristia - e a Filosofia esmera-se em demonstrar tal possibilidade - então é muito mais possível que as duas partes das substâncias individuais, a matéria a forma, possam existir separadamente. Ora, dizer que a matéria é distinta da forma é dizer que ela possui alguma entidade extramental, que ela não é simples possibilidade de ser, que ela é um não-nada.

As noções metafísicas de matéria e forma, tão divergentes entre Scotus e Tomás de Aquino, levam-nos a elaborar Antropologias diferentes. Ambos afirmam que existe uma união substancial entre o corpo e a alma, que constituem, respectivamente, a matéria e a forma do ser humano. Tanto um como outro concordam que a morte significa a dissolução dessa união. Mas, para Tomás, a alma é forma única do composto; para Scotus, o ser independente da matéria faz com que o corpo adquira, além da forma substancial, uma forma própria - a forma corporeitatis - contida virtualmente na forma substancial do composto, e que se atualiza após a dissolução deste. Para Tomás, a alma, forma do corpo, necessita deste para aperfeiçoar-se, pois sem ele não pode exercer seu ato específico, que é o conhecimento. Scotus concorda que assim é pro statu isto, nesta existência, mas não de modo absoluto, pois o ato primeiro de ser da alma - substância espiritual simples - não implica sua união ao corpo. Do mesmo modo, o ato primeiro do corpo não implica sua união à alma. Para Tomás, a união entre alma e corpo acontece para a perfeição da alma; para Scotus, a união entre ambos, que não exclui a perfeição de cada um deles, acontece primeiramente para a perfeição do todo. ${ }^{10} \mathrm{~A}$ doutrina tomasiana não consegue dar conta do conhecimento da alma após a morte: a morte é algo que acontece contra a natureza do homem, e só um milagre divino possibilita à alma exercer sua capacidade intelectiva, quando separada do corpo. A doutrina scotista, afirmando que a alma, substância simples, não pode modificar seu modo de conhecer a não ser modificando seu ser - deixando de ser o que era,

9

Cfr. E. Bettoni. L'ascesa a Dio in Duns Scoto. Milano, 1948. p. 87-112; P. Scapin. "Capisaldi di una antropologia scotista." In: Comissio Scotistica (org.). Deus et homo ad mentem I. Duns Scoti. Acta Tertii Congressus Scotistici Intemationalis. Vindeboanae 29/9-2/10.1970. Roma, 1972. p. 272s.

"Por trás das diferentes concepções de Tomás e Scotus la respeito o primeiro objeto adequado do conhecimento], encontra-se uma Antropologia com acento diverso. Para Tomás, a alma encontra-se unida ao corpo 'devido à determinação de sua natureza'. A separaçăo entre alma e corpo através da morte, pela qual esta unidade natural é suprimida, é, portanto, algo praeter rationem suae naturae (cfr. S. Th. I, q 89, a 1). Para Scotus, a união entre alma e corpo não acontece 'nem por causa da perfeiçăo do corpo, nem somente por causa da perfeiçăo da alma, mas por causa da perfeição do conjunto constituído pelos dois'. Devido à união, nenhuma das partes do conjunto obtém para si uma perfeição que não teria sem a união. Contudo, a união de ambos, tendo por fim o aperfeiçoamento do todo, é algo cheio de sentido (Cfr. Ord. IV, d 45, q 2, n 14; Vivès XX, 305 s). Sem dúvida, a alma possui uma inclinação natural para conferir sua perfeição ao corpo, e, nesta media, está ordenada para o corpo. Contudo, como se trata de uma inclinaçäo natural para um ato segundo, a suspensão desta inclinação, como acontece na morte, não significa uma violência, nem uma imperfeição para a alma em seu ato primeiro. Em qualquer estado a alma permanece em seu ser com igual perfeição (Cfr. Ord. IV, d 43, q 2,n 25s.; Vivès XX., 54s). Por isso, também quando separada do corpo ela possui a capacidade de conhecer o desconhecido, tanto de modo abstrativo como de modo intuitivo [...]. Já para Tomás, a alma separada do corpo não pode mais conhecer abstrativamente as coisas materiais através de um voltar-se diretamente para elas; somente de modo indireto, pela fluminação da luz divina, pode chegar a um conhecimento indireto e confuso (S. Th. I, q 89, a 1 e 3)" (L. Honnefelder. Ens inquantum ens. Münster. 2. ed. 1989. p. 64 s.). 
e passando a ser outro - não precisa recorrer à onipotência divina para explicar o conhecimento após a morte, mas tem que apelar para uma disposição divina, a fim de explicar por que motivo, nesta vida, a alma precisa dos sentidos para conhecer".

\section{Necessitarismo grego e contingência bíblica}

A Cosmologia scotista - como a dos demais medievais - permanece presa à aristotélica. Trata-se de um mundo estático em si mesmo, só movimentado pela ação de uma causa exterior. Aceita em seu conjunto, ela será minada, aos poucos, lenta e imperceptivelmente, por pequenas correções introduzidas através de cada pensador, até não subsistir quase nada mais - as mudanças qualitativas acabaram transformando-se em qualitativas - e surge então o que se costuma chamar de ciência moderna.

Se a Física grega parece reinar soberana, o mesmo, porém, não se pode dizer da Metafísica. Sob as técnicas argumentativas do Organon, valendo-se de Aristóteles, que coloca acima de todos os filósofos, Scotus, mais do que ninguém, vai afirmar o oposto do que apreendeu junto aos clássicos; dirá que o mundo não é necessariamente o que está aí: ele é assim, mas poderia ser diferente; ele é tal porque uma vontade livre assim o quis.

A produção dos seres, para os filósofos - e ao falar em 'filósofos' Scotus entende sobretudo os grandes pensadores não cristãos do passado, principalmente Aristóteles, Avicena e, com algumas ressalvas, também Averróis - é colocada dentro de um nexo de causalidade necessária, que parte da primeira causa e chega até os entes sensíveis. Duns Scotus, ao contráno, observa que, ao se considerar a divindade - que é a primeira causa - deve-se distinguir o que é Deus em si mesmo e o que é em relação a seus efeitos, isto é, com relação ao mundo criado. Em relação a si mesmo, tudo em Deus é necessánio; em relação ao mundo, tudo é contingente. ${ }^{12} \mathrm{~A}$ verdade primeira da necessidade é a essência divina; a dos contingentes, a criação.

A noção de mundo criado não é, porém, uma noção primeiramente filosófica, e sim teológica, o que significa que o problema filosófico da contingência não se esgota de todo na Filosofia, mas possui uma referência fundamental e necessária na Teologia. Ora, isto eqüivale a dizer que a doutrina teológica da criação é a chave para a elaboração do conceito filosófico scotista de contingência. Assim, mais uma vez, nos deparamos com o modo típico dos medievais de fazer Filosofia dentro de um tratado de Teologia. Ao menos desde Tomás de Aquino todos eles, sem exceção, distinguiam perfeitamente os dois âmbitos e sabiam da necessidade

$"$ Cfr. L. A. De Boni. "Cómo alguém que vê à luz de vela". In: Id. (org.) Finitude e transcendência. Festschrift em homenagem a Emildo Stein. Porto Alegre/Petrópolis, 1996. p. 388-406.

12 "Concedo igitur hanc conclusionem quod Deus nihil aliud a se causat necessario, sed voluntarie. Et huius causa est, quia non vult necessario aliquid quod non necessario ordinatur ad finem suum quem necessario vult; et ideo cum nulla creatura sit ordinata necessario et essentialiter ad bonitatem divinam, quae est obiectum voluntatis eius, quia eius bonitas non perficitur ex aliqua creatura, sequitur quod non vult necessario aliquam creaturam, et per consequens non necessario producit aliquam creaturam" (Lect. I, d 8, p 2, q un. n 271 (XVII, 102). 
de respeitar-lhes os limites e as formas de proceder. Mas, quando de suas preleções teológicas - e é bom lembrar que Tomás, Scotus e Ockham eram professores de Teologia - percebiam que seu discurso, para não soar vazio, precisava mostrarse consistente ante as objeções que se lhes pudessem dirigir por parte dos que usando tão somente a razão, ignoravam a revelação.

No pensamento de Scotus, como o reconhecem os estudiosos, a noção de criação desempenha uma função chave, ${ }^{13}$ não tanto enquanto a criação acontece no tempo ou ab aeterno, nem enquanto procede do nada, mas acima de tudo enquanto é obra da liberdade divina, enquanto é contingente. Contingência e criação encontram-se em estreita relação, não podendo existir uma sem a outra. Só Deus é necessário; tudo o que ele produziu ad extra é contingente; por isso, a fim de melhor compreender a constituição do mundo criatural torna-se preciso definir devidamente o que vem a ser contingência.

Ora, o conceito de contingência opõe-se ao de necessidade. Uma análise mais detalhada mostra, porém, que a modalidade da contingência e da necessidade podem aplicar-se em planos diversos. Assim, 'necessidade' pode ser entendida tanto como uma modalidade do ser, no sentido de imutabilidade, quanto como uma modalidade operativa, no sentido de inevitabilidade. Como 'imutabilidade', significa que um ente não pode ser diferente do que é e, neste sentido, cabe somente a Deus. Como 'inevitabilidade', porém, refere-se a um acontecimento que não pode ser evitado, como, por exemplo, o nascer do sol, mas que nem por isso é necessário. Contingência, por sua vez, pode referir-se tanto ao modo entitativo, como ao operativo. No primeiro, possui o sentido de 'mutabilidade', sendo dita das coisas corruptíveis; no segundo, possui o sentido de 'evitabilidade', como acontece no caso dos atos produzidos pela vontade livre. ${ }^{14}$

13 "La verdad de la creación encierra para Escoto una notable serie de implicaciones filosóficas, que él elaborará pacientemente en la ocasión de ello al tratar los temas teológicos, convertiéndolas en los jalones de su pensamiento filosófico. Este reajuste de posiciones de los filósofos inspirado en la doctrina de la creación abarcará en Escoto muchos temas; por exemplo: la afirmación de la contingencia esencial y no sólo existencial de los seres extradivinos; la distinción de la potencia infinita y de la estricta omnipotencia y de la potencia divina absoluta y la potencia ordenada; el carácter sólo contingentemente necesario de las esencias reales y de una parte de la ley moral; la reelaboración del concepto de materia y la revisión de la composición de acto y potencia; la distinción de la naturaleza, sobre todo humana, tomada en absoluto y tomada en el estado en que há sido instituida; el descubrimiento de las auténticas posibilidades metafisicas del hombre; la determinación del objeto próprio del entendimiento humano y la neta distinción entre fisica y metafisica; el planteamiento ajustado de las pruebas filosóficas de la existencia de Dios, etc." (C. Solaguren. "Contigencia y creación en la filosofia de Duns Scoto". In: De doctrina I. Duns Scoti... p. 301 s.

"[...] duplex est contingentia in rebus sicut per oppositum duplex necessitas. Quaedam enim est necessitas immutabilitatis et quaedam inevitabilitatis. Necessitas immutabilitatis est illa, quae non potest aliter se habere, quomodo Deus sit ens necessarium. Necessitas autem inevitabilitatis est illa, qua eventus alicuius rei futurae dicitur inevitabilis, licet in se non sit immutabile nec necessarium, sicut solem oriri cras est necessarium necessitate inevitabilitatis, et alii motus naturales isto modo sunt necessarii et tamen aliter possunt se habere, et ideo non sunt simpliciter necessaria nec immutabilia. Eodem modo per oppositum duplex est contingentia in rebus. Una mutabilitatis, qua aliquid in se potest aliter se habere, ut se habent mobilia et corruptibilia ista. Alia est contingentia evitabilitatis, cuius eventus et esse potest vitari et impediri, cuiusmodi sunt omnes actus voluntatis libere causati $\mathrm{ab} e \mathrm{e}$, nec sunt istae contingentiae eadem, quia non omne contingens primo modo ut generabile quod in se est contingens, contingenter et in minori parte evenit, aliqua tamen ut generabilia et corruptibilia necessario eveniunt et tamen in se non sunt 
Estas definições possibilitam modos diferentes dos termos se relacionarem entre si. De fato, o que é entitativamente contingente, no sentido de 'mutabilidade', acontece necessariamente, pois as coisas corruptiveis necessariamente se corrompem. Já os atos livres da vontade, operativamante contingentes, nunca podem acontecer por necessidade.

Contudo, a grande inovação scotista na noção de contingência encontra-se alhures e sintetiza-se em um texto por demais conhecido, que diz: "Não chamo 'contingente' a qualquer não-necessário ou não-eterno, mas àquele cujo oposto pode acontecer quando ele acontece. ${ }^{n 15}$ A tradição filosófica, desde Aristóteles, tomava como contingente o não-necessánio proveniente de uma falha na propagação do movimento derivado de uma causa necessária. Dentro de uma leitura diacrônica do mundo, que os lógicos modernos chamam de 'estatística', abria-se espaço para os fatos possíveis. A contingência aristotélica admitia a modificação, jamais a possibilidade de colocação do oposto, que é o fundamental para Scotus. Para este, da necessidade da causa primeira não se pode concluir em nãonecessidade nas causas inferiores. A contingência, portanto, tem que ser procurada já no interior mesmo da primeira causa, e não dentro da sucessão de fatos, mas de forma sincrônica: quando se coloca um fato, pode-se colocar seu oposto. Se, pois, quer-se compreender como contingente todo o criado, então, "a compreensão [de contingente] deve libertar-se do esquema temporal (eterno, não-eterno), para ser obtido a partir do fieri inicial dos entes [...] A contingência [...] é a forma de entidade atual que cabe a um ente que pode ser, depois que antes ele não existia (possibilis esse post non esse), isto é, a forma de ser-realmente, que cabe ao ente que em seu ser-realmente é o terminus de um fieri contingente." ${ }^{16}$ Contingente e necessánio são formas opostas de relacionar-se à existência. $\mathrm{O}$ ente necessário possui o ser por si mesmo; o contingente recebe-o de fora.

Neste sentido, Scotus usa diversas vezes o termo 'contingente' como sinônimo de 'possível'. Não do possivel meramente lógico, entendido como "aquilo a que não repugna o ser" (pois também ao ente necessário não lhe repugna o ser), mas no de possivel metafísico, do qual se afirma que, além de não lhe repugnar o

necessaria, sed contingentia. Contingentia autem secundo modo contingenter eveniunt, et generantur nec sunt in se necessaria. Utroque autem modo est contingentia in rebus; nam ex moto aliqua contingenter producuntur et in se etiam contingenter sunt" (Rep. I A d. 39-40; apud Honnefelder, op. cit. p. 57 s. Esta Reportatio é inédita e encontra-se na Biblioteca Vaticana)

15 "[...] non voco hic contingens quodcumque non-necessarium vel non-sempitemum, sed cuius oppositum posset fieri quando illud fit" (Ord. I, d 2, p 1, q 1-2 n. 86; II, 178. De primo princ., c 4, concl. 4, n 56; ed. Kluxen, p. 70). Sobre o significado inovador desta definição de contingência, cfr. S. Knuuttila. "Time and Modality in Scholasticism". In: Id. (org.). Reforging the Great Chain of Being. Dordrecht, 1981. p. 163-257; Id. "Modal Logic". In: N. Kretzmann et al. (org.). The Cambridge History of Later Medieval Philosophy. Cambridge, 1982. p. 342-357; "Duns Scotus and the Foundations of Logical Modalities". In: L. Honnefelder et alii (org.). John Duns Scotus: Metaphysics and Ethics. Leiden, 1996. p. 127-143; H. Veldhuis. "Duns Scotus' Theory of Synchronic Contingency in 'Lectura' I, 39 and is Theological Implications." In: Methodologica ad mentem Ionnis Duns Scoti... p. 571-576.

16 L. Honnefelder,. Scientia transcendens. Die formale Bestimmung der Seiendheit und Realität in der Metaphysik des Mittelalters und der Neuzeit. Hamburg, 1990. p. 59. 
ser, também "não pode ser por si necessário." ${ }^{17}$ Contudo, mesmo após esta especificação, ainda mantém-se uma diferença entre os dois termos, enquanto a nãorepugnância ao ser e o não ser por si necessário ainda não indicam propriamente o contingente, visto que este só é mesmo contingente quando existe realmente, isto é, somente a existência extramental do ente metafisicamente possível permite propriamente chamar de contingente ao ente contingente ${ }^{18}$ pois só esta existência contém o ser após o não-ser (esse post non esse).

A causa primeira da contingência encontra-se, pois, em Deus, que pelo intelecto e a vontade coloca os seres na existência. Ora, a inteligência e a vontade, duas perfeições puras em Deus, diferem entre si no modo de proceder, pois a primeira age por um princípio natural e a segunda, por liberdade. Um princípio natural atua sempre como tal, produzindo sempre determinado efeito. $\mathrm{O}$ mesmo não acontece com a ação determinada pela vontade, por ser esta capaz de querer os opostos. E estes dois modos não se deixam reduzir um ao outro."

A inteligência divina conhece tudo o que pode ser conhecido, tanto em Deus como fora de Deus; portanto, conhece tanto o que existe necessariamente, como o que pode existir. E se não fosse assim, ela não seria perfeita, nem Deus seria ato puro. Já a vontade divina quer livremente quanto quer. Ora, a inclinação da vontade para o bem faz com que o bem necessário, que é o próprio Deus, seja querido por um ato livre da vontade e necessário do querer, pois Deus não pode deixar de querer a si mesmo. Isto significa que a liberdade da vontade exclui a necessidade da natureza, mas não exclui a necessidade do querer. Portanto, pertence à perfeição divina querer necessariamente o que conhece como objeto infinito. No entanto, com relação ao mundo, aos factibilia, com diz Scotus, dá-se algo diferente. Aristóteles e Avicena afirmavam que Deus se relacionava de modo necessário com tudo o que se encontra fora dele. ${ }^{20}$ Scotus argumenta contra eles que é sinal de perfeição querer de modo necessário o bem infinito; contudo, querer do mesmo

17 "Possibile, secundum quod est terminus vel obiectum omnipotentiae, est illud cui non repugnat esse et quod non potest ex se esse necessario" (Ord. I, d 43, q un., n 7; VI, 354). "Omne productum possibile est produci, sed quod possibile est produci habet aliquam possibilitatem; sed tale non est ex se necesse-esse; ergo nullum productum est ex se necesse-esse [...] Et omne capiens esse post non-esse secundum tempus aut secundum naturam, est ex se possibile non esse, et non ex se necesse-esse; igitur nullum productum est ex se necesse-esse" (Lect. I d 2, p 2, q 1-4, n. 149 s; XVI, 163)

"Contingens enim numquam est formaliter contingens nisi quando est, contingenter est" (Ord. III, d 18, q un., n. 17; Vivès, 693). "Si dicas, 'effectus dicitur contingens, quia potest non fieri', contra: prius non fuit ens; ergo nec prius actu effectus contingens. Loquimur enim nunc de contingentia, prout est modus entis in actu quando est in actu et pro illo nunc pro quo est in actu" (Quaest. in Met. IX, q 15, n 60; OPh IV, 694).

19 "Necessitas naturalis non stat com libertate. Quod probo: quia natura et voluntas sunt principia activa habentia oppositum modum principiandi, ergo cum modo principiandi voluntatis non stat modus principiandi naturae; sed libere voluntas vuit finem, ergo non potest necessitate naturali velle finem, nec per consequens aliquo modo necessario" (Ord. I, d 1, p 2, q 2, n 80; II, 60). A importância que Scotus dava ao problema fá-lo retomar várias vezes o tema, que ocupa toda a última questão de seu comentário à Metafísica (Quaest. in Met. IX, q. 15; OPh IV, 677-699).

20 "Itaque concordant Arsitoteles et Avicenna in sequentibus ex uno príncipio falso - in quo concordant - scilicet quod Deus necessario se habet ad quidlibet quod est extra se, ad quod immediate vel mediante immutabili comparatur" (Ord. I, d 8, p 2, q. un., n 255; IV, 297). 
modo um bem finito é sinal de imperfeição. ${ }^{21}$ Ao se considerar a ação de Deus no mundo, não é apenas a natureza do agente divino que deve ser levada em conta, mas também a do objeto sobre o qual recai tal ação: sendo necessário o objeto, será necessário o querer da vontade divina; sendo contingente, será contingente o modo de querer da vontade. Ora, tudo o que não é Deus situa-se no reino da contingência e, por isso mesmo, é querido por Deus também de modo contingente, pois seria uma forma de imperfeição de querer da vontade, se esta viesse a querer de modo necessário aquilo que por si é contingente. "A deficiência do modo de ser do possível corresponde a contingência no querer este possível por parte da vontade divina"."2

Mas por que Deus quis este e não seu oposto, ou este e não aquele? A pergunta é classificada por Scotus entre os questionamentos tidos por Aristóteles ${ }^{23}$ como próprios daqueles a quem falta erudição, pois, diz Scotus, a vontade não possui um princípio anterior que explique porque ela quer isto ou aquilo. Ela quer porque a vontade é vontade, ela quer porque quer, ${ }^{24}$ não existindo um porquê anterior. Nisto, porém, exclui-se qualquer forma de irracionalismo na liberdade da vontade, pois esta não exerce a liberdade de forma cega, segundo um modelo decisionista; sua ação efetua-se sempre dentro dos parâmetros da racionalidade, pois decide-se a partir daquilo que a inteligência lhe apresenta como possivel de ser querido.

Cabe aqui uma pergunta: no modo de ver de Scotus, o que diriam Aristóteles, Avicena e os demais filósofos ante esta argumentação em favor da contingência? A pergunta tem sentido, pois, por mais de uma vez, a coloca de forma indireta e deixa entrever a resposta. Na Lectura I, quaestio 8 - e de modo correspondente na Ordinatio - ele reconstrói os passos da argumentação necessarista, a partir da afirmação de que existe uma causa que causa necessariamente, porque é uma causa necessária. ${ }^{25}$ Henrique de Gand já havia feito a crítica à argumentação dos filósofos e Scotus a retoma, mas, para tanto, deve modificá-la profundamente. Sua principal ressalva ante o texto do mestre belga é que este vê incoerência no fluxo da argumentação greco-árabe, enquanto Scotus a considera consistente, discordando dela tão somente no ponto de partida: enquanto os filósofos afirmam a

${ }^{21}$ "Voluntas infinita necessario habet actum circa obiectum infinitum, quia hoc est perfectionis: et pari ratione non necessario habet actum circa obiectum finitum, quia hoc esset imperfectionis; nam imperfectionis est necessario determinari ad posterius, et perfectionis requisitae est sic determinari ad prius, et perfectionis concomitantis ad illud quod est simul natura" (Quodl. 16, n 9; Vivès XXVI, 194). L. Honnefelder. Scientia transcendens.... p. 90. Cfr. C. Solaguren. op. cit. p. 313.

Aristóteles. IV Metafísica, c 4; 1006a 5-8.

"Immediatum autem est voluntatem velle hoc, ita quod non est aliqua causa inter ista, sicut est immediatum calorem esse calefactivum (sed hic naturalitas, ibi libertas), et ideo sicut huius 'quare voluntas voluit' nulla est causa nisi quia voluntas est voluntas" (Ord. I, d 8, p 2, q un., n 299; IV, 325; cfr. Quaest. in Met.IX, q 15, n 24; Oph, IV, 681).

"Est igitur conclusio, quam isti [Aristoteles et Avicenna] concorditer tenent, quod ista perpetua et incorruptibilia sunt possibilia ex se, et tamen necessaria, quia causa aliqua quae necessario causat, quae causa necessaria est" (Lect. I, d 8, p 2, q un., n 236; XVII, 90). Cfr. Ord. I, d 8, p 2, q un., n 255 (IV, 297): "Itaque concordant Aristoteles et Avicenna in sequentibus ex uno principio falso - in quo concordant - scilicet quod Deus necessario se habet ad quidlibet quod est extra se ad quod immediate vel mediate immutabili comparatur." . 
necessidade dos seres produzidos pela causa primeira, os teólogos afirmam a contingência ${ }^{26}$ Ora, aceitando que há coerência interna na argumentação dos filósofos, e não querendo impor-lhes cơisas mais absurdas que aquelas que eles mesmos disseram, ou que se deduzem de suas palavras, ${ }^{n}$ pode-se demonstrar que o ponto de partida dos filósofos está errado? Creio que a resposta scotista será um claro 'não', pois o ponto de partida que lhes contrapõe fundamenta-se na revelação divina e, por isso, está fora do âmbito do trabalho da simples razão. Ora, já no Prólogo da Ordinatio, ao perguntar-se sobre a necessidade da revelação, havia observado que os argumentos teológicos em favor da tese não podiam ser qualificados de provas, mas antes de persuasões, que não poderiam ser usadas contra quem ignora a revelação. ${ }^{29} \mathrm{O}$ mesmo se repete agora, quando observa sobre alguns argumentos de Henrique de Gand, que "esta prova não é conclusiva para os filósofos" ou que "esta prova, embora seja boa para os católicos, contudo não convence os filósofos. ${ }^{n \approx}$ As técnicas de argumentação, que Oxford desenvolvera em grau elevado no final do século XIII, exigiam rigor nos passos que eram dados, devendo-se sempre levar em consideração as colocações do oponente. Ora, acima de qualquer relativismo, nem sempre um argumento, que parece convincente para um, é igualmente convincente para outro. "Argumentos e provas tomam-se relativizados pessoalmente." ${ }^{\text {*o }} \mathrm{O}$ que Scotus faz é propor uma leitura altemativa, que julga correta e que, argumentativamente, toma como muito mais provável que a dos filósofos, mas nem por isso nega o valor intrínseco da leitura de seus oponentes.

\section{A liberdade como noção chave da Antropologia scotista ${ }^{31}$}

0 que age por natureza, age por necessidade, sempre do mesmo modo; o que age por vontade, age livremente: age de um modo, mas pode agir de outro; como também pode não agir. Ora, a partir da análise de nossos atos interiores Scotus constata que existe um duplo movimento nas potências da alma: um natural, e

\footnotetext{
25 "Non igitur est altercatio inter nos [theologos] e illos [philosophos] nisi in isto fundamento eorum" (ibid. n 237). Sobre o modo como Scotus reconstrói a argumentação filosófica e o valor que concede a ela, e as ressalvas ante Henrique de Gand, cfr. A.Vos. "Duns Scotus and Aristotle". In: Id. (org.). John Duns Scotus - Renewal of Philosophy. Amsterdam, 1998. p. 57-71.

"Nolo eis imponere absurdiora quam ipsi dicant vel quam ex dictis eorum necessario sequantur, et ex dictis eorum volo rationabiliorem intellectum accipere quem possum" (Ord. I, d. 8, p 2, q un., n 250; IV, 294).

28 Ord. I, Prol, p 1, q un., n 12; I, 9. Cfr. L. A. De Boni. "Filosofía y Teología en Duns Escoto." In: J. A. Aertsen e A. Speer (ed.). Was ist Philosophie im Mittelalter. Berlin, 1998. p. 403-413.

${ }^{29}$ "Ista ratio non concluderet philosophis" (Lect. I, d 8, p 2, q. un., n 246; XVII, 92). "Ista ratio, licet sic bona sit catholicis, non tamen convinceret philosophis" (ibid. n 251, p. 95).

A. Vos. Op. cit. p. 72.

Entre os inúmeros trabalhos sobre a liberdade humana em Duns Scotus, cfr., além da obra acima citada de E. Gilson, A. Wolter. Duns Scotus on the Will and Morality. Washington, 1986 (trata-se de um trabalho pioneiro, que apresenta e comenta os principais textos de Scotus sobre a Ética); W. Hoeres. Der Wille als reine Vollkommenheit nach Duns Scotus. München, 1962 lo texto mais importante, a meu modo de ver); I. Gavran, "The Idea of Freedom as a Basic Concept of Human Existence According to John Duns Scotus". In: Comissio Scotistica (org.). De doctrina Ioannis Duns Scoti. Acta Congressus Scotistici Internationalis. Oxonii et Edimburgi, 11-17.09.1996. vol. 2. Roma,
} 
outro livre. E como são duas as potências superiores da alma, a inteligência e a vontade, se esta age livremente, então aquela deve agir de modo natural, pois os dois princípios do agir - ser naturalmente ativo e ser livremente ativo - não se deixam reduzir um ao outro. ${ }^{22}$ Tomando por pano de fundo a divisão aristotélica entre ação natural e ação racional, tal como apresentada na Metafísica $^{\text {s }}$ deve-se dizer, então, que a inteligência situa-se no modo de agir da natureza, não sendo 'racional' no sentido dado por Aristóteles, pois encontra-se determinada ao inteligir e não está em seu poder inteligir ou não inteligir; a racionalidade cabe à von: tade, pois somente esta pode determinar-se para os opostos. ${ }^{\text {h }}$ Não se trata, de maneira alguma, de ignorar ou diminuir a importância da inteligência, pois, como veremos, sem ela não haveria ato livre da vontade, mas tão somente de mostrar como o enunciado de Aristóteles precisa ser reformulado, na medida em que a inteligência é ad unum, e não ad opposita.

Isto posto, cabe dizer, em primeiro lugar, que a vontade é formalmente livre, isto é, independentemente de quaisquer outros fatores, ela possui sempre o domínio sobre seus atos. Sob este aspecto ou ela é livre, ou não é, não existindo graduação de maior ou menor liberdade. Embora, pois, a vontade humana seja limitada, pode ela ser considerada de modo formal e, como tal, ela é uma perfeição simples, da qual se exclui a limitação. ${ }^{35}$ Ela é livre por essência. A leitura aristotéli-

1968. p. 645-669; C. Markoc. "Primatus voluntatis iuxta mentem Duns Scoti". Ibid. p. 605-612; R. Zavalloni. "Personal Freedom and Scotus' Voluntarism". Ibid. p. 613-627; W. Hoeres. "Die Hinordnung des menschlichen Verstandes auf die Wahrheit und die Möglichkeit seines Abfalls von Gott und der Ordnung der Dinge nach Duns Scotus". In: Comissio Scotistica (org.). Deus et homo ad mentem I. Duns Scoti. Acta Tertili Congressus Scotistici Internationalis. Vindobonae, 28/09. 02.10.1970. Roma, 1972. p. 513-550; W. Kölmel. "Wille und Freiheit in der Lehre des Duns Scotus". Ibid. p. 343-358. R. Lawrence. "John Duns Scotus and the Concept of Human Freedom". Ibid. p. 317-325. A. Marchesi. "Singolarità irrepetibile e continua perfettibilità della persona umana, fondata nella volontà libera secondo Duns Scoto". Ibid. p. 371-377; A. Wolter. "Native Freeddom of the Will as a Key in the Ethics of Scotus". Ibid. p. 359-370. W. Borowski. "Die Freiheit nach den Psychologen, den Philosophen und den Theologen und nach Duns Scotus". In: Comissio Scotistica (org.). Regnum hominis et regnum Dei. Acta Quarti Congressus Scotistici Internatiionalis. Paduae, 24-29.09.1976. vol. 2. Roma, 1978. p. 567-576; R. Lawrence. "The Contemporary Relevance of Duns Scotus' Doctrine of Human Freedom". Ibid. p. 534-544; E. Rivera de Ventosa. "Los caminos de la liberdad en J. Duns Escoto y J. P. Sartre". Ibid. p. 545-565; R. Lawrence. "A Comparison of Duns Scotus and Thomas Aquinas on Human Freedom of choice". In: Comissio Scotistica (org.) Homo et mundus. Acta Quinti Congressus Scotistici Internationalis. Salmanticae, 21-26.09.1981. Roma, 1984. p. 265-272. R. Rosini. "La suprema distinzione tra Dio e il mondo in Duns Escoto". Ibid. p. 331-343; 1. Manzano. "In via Scoti: la via 'libertatis'". In: Methodologica ad mentem Joannis Duns Scoti... p. 246-259; M. McC. Adams. "Duns Scotus on the Will as Rational Power". Ibid. p. 839-854; E. Dekker. "Scotus's Freedom of the Will Revised". In: E. P. Bos (org.). John Duns Scotus. Renewal of Philosophy. Amsterdam, 1998. p. 113-121.

32

"i...] esse naturaliter activum et esse libere activum, sunt primae differentiae principii activi, unde voluntas est principium activum libere. Non magis igitur potest voluntas esse naturaliter active quam natura, ut est principium distinctum contra voluntatem, potest esse libere active" (Quodl. 16, n. 15; Vivès XXV, 199).

Aristóteles. IX Metaphysica, c 2; 1046b 2-4.

Quaest. in Met. IX, q 15; OPh IV, 684-ss.

${ }^{35}$ "Libertas absolute est perfectio simpliciter; unde formaliter ponitur in Deo [...] Libertas in nobis est limitata; potest tamen considerari secundum rationem eius formalem sine illa limitatione, et tunc non est perfectio limitata, sed perfectio simpliciter" (Ord. II, d 7, q un. n 9; Vivès XII, 383). A noção de perfeição simples Scotus a toma de santo Anselmo, modificando-a, porém, e definindo-a como: 
ca explica o modo natural de agir da potência ante o objeto: não havendo impedimento, a ação será sempre a mesma sobre o mesmo objeto: o fogo sempre queimará a estopa, o sol sempre secará a lama e derreterá neve. Mas o mesmo modelo teórico tem dificuldade em explicar como é que, nos animais, 0 apetite reage ante o objeto que se lhe apresenta e, mais ainda, como se explica a ação do apetite racional, isto é, da vontade. Scotus não aceita solução tomista, que atribui à deliberação da razão a superação do obstáculo existente entre a inclinação da vontade para seu objeto e a ação para alcançar tal objeto. Para ele, é necessário distinguir dois modos de ser da potência: de um modo, ela encontra-se indeterminada, ou igualmente determinada, tanto para um como para outro dos opostos, porque carece de algo que seja suficiente para determiná-la à ação; de outro modo, a faculdade pode ser capaz de opostos por superabundância de suficiência $^{3}$. Este último é o caso da vontade, que não se deixa constituir exaustivamente pela tendência para nenhum objeto; pelo contrário, ela possui em si mesma a capacidade de agir ou de não agir, de agir de uma forma ou de outra, isto é, por si mesma, sem ser movida por nada de exterior, ela é capaz de querer um objeto, ou seu contraditório, um objeto ou seu contrário. No mesmo instante em que a vontade decide-se à ação (como, por exemplo, decide-se a caminhar), ela pode decidir-se ao contrário (como, por exemplo, a ver um filme), ou ao contraditório (a não caminhar). E não existe uma causa que a leve a decidir-se a um ou a outro, porque a causa de sua ação encontra-se nela mesma. Como já foi observado acima, ela assim se decide porque quer, porque a vontade é vontade. E tal como não existe causa anterior a determiná-la, também não existe exemplo para explicar seu modo de ser, porque a vontade é a única potência ou faculdade livre, todas as demais são naturais, e exemplos tomados das potências naturais não se prestam para explicar o agir livre da vontade. ${ }^{n}$

Formalmente considerada, portanto, a vontade é "livre por essência. ${ }^{38}$ Ela se constitui em uma "autogênese humana", pois "nada além da vontade é causa total da volição na vontade. ${ }^{n 40}$ Como tal ela não pode ser jamais perdida pelo homem, porque deixar de ser livre eqüivale a deixar de ser homem." Por isso, Deus não pode tirar do homem a liberdade, a menos que lhe tire também a humanida-

\footnotetext{
"Perfectio simpliciter est, quae in quolibet habente ipsam melius est ipsam habere quam non ipsam habere" (Quodl. V, n 13; Vivès XXV, 210).

36 "[...] est quaedam indeterminatio insufficientiae, sive ex potentialitate et defectu actualitatis, sicut materia non habens formam est indeterminata ad agendum actionem formae; est alia superabundantis sufficientiae, quae est ex illimitatione actualitatis, vel simpliciter vel quodammodo. Primo modo indeterminatum non reducitur ad actum nisi prius determinetur ad formam ab alio; secundo modo indeterminatum potest se determinare [...]. Indeterminatio autern quae ponitur in voluntate non est materialis, nec imperfectionis in quantum ipsa est activa, sed est excellentis perfectionis et potestativae, non alligatae ad determinatum actum" (Quaest. in Met. IX, q 15, n 31 e 34; OPh IV, $683 \mathrm{~s})$. Cfr. E. Dekker. Op. cit. p. 115; A. Wolter. Duns Scotus on the Will and Morality. p. 158s. "liberam per essentiam" (Ord. I, d 17, p 1, q 1-2, n 66; V, 169; cfr. Ord. II, d 39, q 2, n. 2-3 e 5, Vivès XIII, 410-412 e 415-416).

W. Kölmel. "Wille und Freiheit...", op. cit. p. 348

"[... [ nihil aliud a voluntate est causa totalis volitionis in voluntate" (Ord. II, d 25, q un, n 22; Vivès XIII, 224).

41 Ord. IV, d 49, q 6, n 9 (Vivès XXI, 187 s).
} 
de. ${ }^{2}$ Nem mesmo o ato de querer o fim último escapa-lhe do controle. Para Tomás de Aquino, a vontade é livre na escolha dos meios para alcançar o fim último, mas não no querer tal fim, que é o bem supremo, para o qual ela se inclina necessariamente. Duns Scotus discorda; para ele, a vontade é livre tanto na escolha dos meios, como na decisão de dirigir-se para o fim último. Sem dúvida, ela não pode odiar o fim último, não pode detestar a felicidade, pois tende 'naturalmente' para ela, mas pode, por exemplo, decidir por abster-se de qualquer ação para atingila. ${ }^{43} \mathrm{E}$ nem mesmo os bem-aventurados, no céu, perdem sua liberdade: eles continuam capazes de querer ou de não querer a felicidade, pois a visão beatífica não lhes destrói a liberdade, já que o ato de amor é um ato de adesão ativa da vontade ao objeto. A impecabilidade da vontade no céu deve-se à graça divina, não a uma mudança no modo de ser da vontade.

Mas a liberdade da vontade não eqüivale a alguma forma de arbitrariedade. A vontade faz sua escolha baseada no que lhe apresenta a inteligência. Nesta questão, duas posições antagônicas haviam sido colocadas: de um lado, a de Tomás de Aquino, para quem há uma superioridade do ato de inteligir sobre 0 ato de querer; de outro, a de Henrique de Gand, que considerava a inteligência não propriamente como uma causa no ato de querer, mas como simples conditio sine qua non. Scotus discorda de Tomás e afirma que o intelecto conhece o objeto e 0 apresenta à vontade, faltando, porém, ao intelecto o que é o fundamental na ação, que é a escolha. Mas discorda também de Henrique de Gand e diz que o intelecto não é apenas condição, mas verdadeira causa no conhecer e, para tanto, vale-se da noção de causas essencialmente ordenadas, quando duas ou mais causas precisam ser necessariamente postas, embora de modo diferente, para que um efeito possa surgir. Uma só causa não consegue produzir o efeito total - como caso da ação do pai e da mãe no ato de gerar, ou do intelecto e do objeto no de conhecer ${ }^{\mu}$ - que é o efeito total - mas não há proporção de igualdade entre eles, sendo cada um deles concausa de maneira específica. Do mesmo modo, diz ele, "o intelecto depende da volição, como de causa parcial superior; já a vontade, ao contrário, depende da intelecção, como de causa parcial subserviente". ${ }^{45}$ Há uma precedência cronológica da intelecção sobre a volição, tal como o afirma a tradição, ao

42 Ibid. p. 232 ss.

43 "Non potest voluntas odire vel detestari beatitudinem, quod est verum; sed ex hoc non sequitur quod necessario vult beatitudinem. [...] non sequitur ergo necessario volo beatitudinem, quia nullum velle necessario elicitur a voluntate" (ibid. q 10, n 10; XXI, 333).

4 "Causas essencialmente ordenadas" constitui um dos pontos-chaves da metafisica scotista. Cfr. A respeito: R. Wood. "Ockham on Essentialy-Ordered Causes. Logic Misapplied." In: W. Vossenkuhl e R. Schönberger. (org.) Die Gegenwart Ockhams. Weinheim, 1990. p. 25-50; L. A. De Boni. "Bedeutung und Grenzen des aristotelischen Denkens im Gottesbeweis von Duns Scotus". In: L. Honnefelder et al. (org.) John Duns Scotus - Metaphysics and Ethics. Leiden, 1996. p. 455-473. Sobre a atuação do intelecto e do objeto no conhecimento, cfr. R. Messner. Schauendes und begriffliches Erkennen nach Duns Scotus. Freiburg i. Br., 1942.

45 "Intellectus dependet a volitione, ut a causa partiali, sed superiori; e converso autem voluntas ab intellectione, ut a causa partiali, sed subserviente" (Ord. IV, d 49, q. ex latere, n. 18; Vivès XXI, 155). 
dizer que 'nada é querido sem que antes seja conhecido', e, por isso, não existe ato de vontade sem que haja antes o correspondente ato de intelecção."

Mas o que é proposto pela inteligếncia apresenta-se à decisão da vontade de modo neutro, não leva em si coação nenhuma tanto para os meios como para 0 fim; é a vontade que livremente decide. A vontade manda ao intelecto que se volte para o conhecimento, mas 0 ato de conhecer é um ato exclusivo do intelecto, sem nada a ver com a vontade; do mesmo modo, o intelecto propõe o objeto à vontade, mas o ato de querer é exclusivo da vontade, no qual o intelecto não se imiscui."

Com isso, porém, Scotus está negando um velho princípio do saber aristotélico-escolástico, que se resume na frase: Omne quod movetur ab alio movetur. Para ser movida livremente, a vontade precisaria de uma causa livre que a movesse, pois se a causa eficiente que move não é livre, não pode também transmitir a liberdade. Sem dúvida, a razão da liberdade encontra-se na causa eficiente primeira, que é Deus, o qual cria a vontade dotada de liberdade. Mas, em seu agir livre, como se disse acima, a causa primeira da vontade encontra-se nela mesma: para agir livremente, a vontade não é movida por outro, ela move a si mesma.

Formalmente, pois, a vontade é livre e não pode haver nela grau maior ou menor de liberdade. Contudo, materialmente, nas situações concretas, existe maior ou menor liberdade." Para desenvolver este tema, Scotus vale-se, a seu modo, de uma distinção de santo Anselmo e afirma que na vontade devem ser distinguidas duas affectiones, isto é, duas afeições ou inclinações 'naturais' para o bem: a affectio commodi e a affectio iustitiae. ${ }^{50}$ Pela primeira, a vontade age em vista daquilo que se lhe apresenta como o bem de seu próprio interesse, isto é, de sua perfeição e de sua felicidade; pela segunda, age em vista da bondade e do valor intrínseco do objeto, independente do que este lhe possa trazer de vantagem. Ambas as tendências são intrínsecas à vontade e, portanto, tanto em uma como em outra ela mantém sua capacidade de voltar-se para bens diferentes, incompossíveis. Assim, a affectio commodi pode escolher entre ir ao cinema ou ler um livro, e a affectio iustitiae, entre fazer-se religioso numa ordem contemplativa ou ingressar numa instituição que trabalha com os aidéticos.

Estas inclinaçōes, em teoria, não são exclusivas entre si. Pelo contrário, como o agente é sempre um bem em si mesmo, a affectio commodi encerra em si também a affectio iustitiae do mesmo modo, esta, ao realizar-se, implica também a realização daquela. Ao procurar seu próprio interesse a vontade não exclui a pro-

\footnotetext{
46 "Volitio est effectus posterior intellectione naturaliter [...] et propter illum ordinem necessarium non potest causari volitio a voluntate, nisi prius causetur ab intellectu intellectio" (Ord. II, d. 25, q un. n 19; Vivès XIII, 221).

"Voluntas non causat actus intelligendi, sicut concludit ratio, sed facit tantum, quod intellectus convertitur ad illud considerandum" (Collationes II, n 8; Vivès V, 147).

49 "Primam contingentiam quaerere in voluntate divina" (Ord. I, d 38 s, q 1-5, appendix A; VI, 416).

4. Gavran (loc. cit., p. 644; 651-663), referindo-se a M. J. Adler, distingue entre 'liberdade natural' (natural freedom) e liberdade adquirida (acquired freedom). E. Dekker (loc. cit., p. $118 \mathrm{~s}$.) distingue entre liberdade formal e material ou, como equivalente, entre liberdade abstrata e liberdade situada. Ord. II, d 39, q 2, n 5 (Vivès XIII, 415 s.); Ord. III, d 18, q un., n 5-6 (Vivès XIV, 664s); Rep. III, d 26, q un. n 19 (Vivès XXIII, 474).
} 
cura do valor objetivo que seu ser possui pelo fato mesmo de ser; e, ao amar a Deus pelo que ele é em si mesmo, não exclui que este amor seja também a suprema realização de tudo o que lhe possa advir em vantagem pela felicidade de contemplar beatificamente a divindade. $\mathrm{Na}$ prática, porém, as duas tendências podem entrar em conflito. No caso, em vez de propor uma norma de conciliação entre as duas tendências, Scotus reporta-se a Aristóteles, para quem a inclinação natural é sempre e tão somente inclinação para a própria perfeição, ${ }^{51}$ isto é, visa tão somente ao próprio interesse. Por isso mesmo, a este nível o apetite natural da vontade assemelha-se ao apetite dos seres irracionais. Esta inclinação primeira, como expõe A. Wolter, confere à vontade tão somente sua perfeição genérica, como apetite racional, enquanto a affectio iustitiae lhe confere a diferença especifica, pela qual é capaz de determinar-se livremente, de uma forma objetiva, para o bem. ${ }^{52}$ Sem esta, a affectio commodi seria apenas condição necessária, mas não suficiente para classificar os atos como moralmente bons. Novamente, portanto, o paradigma aristotélico é modificado. A inclinação para a justiça é uma tendência da vontade que a faz transcender-se a si própria.

As noções de affectio commodi e affectio iustitiae, colocadas a nível de natureza, independente da elevação pela graça, constituem um dos fundamentos da ética scotista, na qual é recorrente o tema da liberdade. Sob este enfoque abre-se espaço para a análise da relação entre a privação da liberdade civil - a escravidão - e as inclinações da vontade para o próprio bem e para a justiça. O tema embora abordado obliquamente, ao tratar das obrigações mútuas entre o servo e o senhor, mantém-se na linha de coerência dos demais textos do autor. Por brevidade, observamos apenas que Scotus é o medieval que maiores restrições faz à privação da liberdade, pois esta "é a coisa mais preciosa e mais nobre que há na alma e, conseqüentemente, no homem". ${ }^{\text {s }}$ Por isso, parece-lhe loucura que alguém queira fazer-se escravo e, opondo frontalmente a Aristóteles, é-lhe inadmissivel que alguém seja escravizado a ponto de não possuir mais capacidade de decisão, pois "o escravo, em seu ato, não é apenas conduzido, mas também conduz, pois embora seja servo, continua sendo homem e, portanto, senhor de livre-arbítrio". ${ }^{\text {sh }}$

51 "De isto appetitu non libero sed naturali patet, quia voluntas necessario sive perpetuo et summe appetit beatitudinem et hoc in particulari [...] Si enim natura appetat suam perfectionem, ergo summe appetit suam perfectionem summam. [...] Cum ergo tamen summa perfectio voluntatis sit beatitudo, sequitur quod voluntas ut natura summe appetit eam" (Ord. IV; supl d 49, q 9-10; (Vivès XXI, $318 \mathrm{~s})$.

52 A. Wolter. Duns Scotus on the Will and Morality p. 40. I. Gavran (loc. cit. p. 657) explicita assim esta relação: "If the affectio commodi is a prolongation of the natural tendency into the intellectual level, the affectio iustitiae doesn't mean an addition to it; it belongs to the will essentially, as if it were its ultimate difference, specifying its being. The will is both the affectio commodi as a natural inclination, as an intellectual appetite, and the affectio iustitiae, owing to the fact that it is a spiritual faculty." "Libertas est pretiosissima res et nobilissima quae est in anima, et per consequens in homine" (Rep. IV, d 15, q 4, n 38; Vivès XXIV, 246).

\section{4} “[... servus non est domini quantum ad omnia, quia sui iuris est ad comedandum et bibendum et dormiendum, et breviter ad quoscumque actus exercendum quibus non subtrahuntur domino debita servitia. [...] Et quod Philosophus dicit de servitute illa maledicta, qua servus est sicut pecus, intellige potest quod sit domini sui sicut possessio vel pecunia; non tamen quod in actibus suis 
Enfim, pode-se perguntar sobre a possibilidade de a vontade agir contra os ditames de suas duas inclinações e da razão. Sem dúvida, como se viu, está sempre na possibilidade da vontade a abstenção da ação, mesmo quando se trata do bem supremo. Por outro lado, é impossivel que a vontade queira o mal sob a razão de mal. Entretanto, ela pode optar por uma forma de ação que é contra a razão e contra as duas affectiones que lhe são inerentes. É o caso, por ele citado, daquele cristão que sabe que a fornicação não se ordena para a felicidade eterna $\mathrm{e}$, no entanto, mesmo sabendo, prefere a fornicação.$^{55}$ Esta decisão, tomada conscientemente, é uma afeição a um bem inferior, que ofende tanto a affectio commodi como a affectio iustitiae. E, no entanto, ela acontece. Alguém, contudo, poderia argumentar que, em tal caso, o peso do apetite sensível foi muito forte, levando a vontade a ceder. Scotus admite a objeção e, com relação a isto, classifica os pecados em três espécies diferentes: a) eles podem sofrer a influência do apetite sensível; b) podem ser devidos a erro da razão; c) podem provir de uma deliberação plena da vontade ${ }^{56}$ Esta última espécie é um caso limite, que mostra o abismo da liberdade humana em sua capacidade para o mal. Quem não conhece aquele texto de Agostinho, nas Confissões, contando do roubo das peras? $\mathrm{O}$ fato, que poderia parecer insignificante, é o ponto de partida para sua reflexão a respeito da malícia de certas ações humanas. As peras não foram roubadas para serem comidas, nem para prejudicar o proprietário, nem por outro motivo semelhante: elas, ainda verdes, foram roubadas só para serem roubadas, sem nenhuma outra finalidade. Foram tão somente um pequeno furto, capaz contudo de revelar o que é a maldade humana. E aqui, de novo, Scotus afasta-se do modelo aristotélico: a vontade, mesmo quando se trata de seus próprios objetos, não necessariamente ama acima de tudo o que é melhor ou evitá acima de tudo o que é pior.

tantummodo ducatur et non ducat, quia quantumcumque sit servus, tamen homo est et ita liberi arbitrii, ex quo patet magna crudelitas in prima inductione servitutis, quia hominem arbitrio liberum et dominum actuum suorum ad virtuose agendum facit quasi brutum, quia nec libero arbitrio utentem nec potentem virtuose agere" (Ord. IV, d 36, q 1, a 2; Vivès XIX, 453). Cfr. I. Gavran. Loc. cit. p. 663-668; L. A. De Boni. "Ética e escravidảo na Idade Média". In: AA. VV. Ética e trabalho cinco estudos. Caxias do Sul, 1989. p. 41-44.

55 "[...] potest aliquis fidelis concipere beatitudinem in particulari, ut quod sit respectu fruitionis essentiae divinae, quae est una in tribus personis, et potest concipere aliquid quod nullo modo ordinatur ad illam beatitudinem, ut fornicationem; stante autem ista apprehensione de fornicatione, quod nullo modo sit ordinabilis ad beatitudinem, potest appetere fornicationem. Sed sic appetendo fornicationem, non appetitur in ordine ad beatitudinem" (Rep. Par. IV, d. 49, q 9, n 18; Vivès, XXIV, 667 s.).

"Voluntas enim, quia coniuncta est appetitu sensitivo, nata est condelectari sibi, et ita peccans occasionaliter ex inclinatione appetitus sensitivi ad suum delectabile, peccat passione quod dicitur peccatum ex infirmitate sive impotentia, et est appropriate in Patrem, cui attrribuitur potentia. Ipsa etiam agit per cognitionem intellectualem, et ideo ratione errante, ipsa recte non vult, et peccatum eius ex errore rationis dicitur peccatum ex ignorantia contra Filium, cui attribuitur sapientia. Tertium enim esset peccatum ipsius secundum se ex libertate sua, non condelectando appetitui sensitivo, neque ex errore rationis, et istud est recte ex malitia, et appropriate contra Spiritum Sanctum, cui appropiatur bonitas. Si tamen non ponatur voluntas creata posse velle malum sub ratione mali, adhuc potest assignari peccatum ex certa malitia quando voluntas ex libertate sua absque passione in appetitu sensitivo et errore in ratione peccat. Ibi enim est plenissima ratio peccati, quia nihil aliud a voluntate alliciens eam ad malum, non tamen ex malitia, ita quod voluntas sic peccans tendat in malum inquantum malum, sed ex pura libertate sine aliqua occasione extrinseca, eligit sibi malum velle" (Ord. II, d 43, q 2, n 2; Vivès XIII, 493 s.). 
Como observa M. McC. Adams a respeito, tomando um paradigma aristotélico para analisar a faculdade natural e seu agir, Scotus separa-se de tal modelo em três momentos fundamentais. "[...] for Scotus, will is causally bound neither to seek its natural object (because if its power not to act), nor to pursue its own advantage (because of its power not to act as well as its affectio iustitiae). It is not even bound to fellow its own best judgement (by its power to act contrary thereto). And Scotus celebrates the will as better than our 'Aristotelian' powers, hails created rational natures as better for being able to overreach their own advantage, when he identifies the 'deviant' features of will power with freedom". ${ }^{.7}$

Quando, porém, a vontade é compreendida como algo que não se deixa determinar por nada fora dela, cada ser humano sente-se não só como senhor de seus atos, mas como entregue a si mesmo em suas decisões. Sob este aspecto, a Geworfenheit heideggeriana, o jetté-là sartreano encontram um precedente na ultima solitudo scotista. Duns Scotus, ao perguntar-se sobre a noção de pessoa, deparou-se com a definição boeciana, dizendo que a pessoa é uma "substância indivisa de natureza intelectual" ${ }^{58}$ Ora, esta definição parece-lhe insuficiente porque, por um lado, poderia ser atribuída à alma humana separada ou à divindade $\mathrm{e}$, no entanto, nem a alma, nem a divindade constituem propriamente pessoa; por outro lado, tal definição refere-se às segundas intenções, isto é, àquelas intenções que não são as do ser existente, mas que provêm da reflexão do intelecto sobre o ser. ${ }^{\varpi}$ Por isso, parece-lhe preferivel a definição elaborada por Ricardo de São Víctor no século anterior, dizendo que a pessoa é a "existência incomunicável de natureza racional". ${ }^{\circ} \mathrm{O}$ que chama a atenção na posição de Scotus é o fato de ele, um essencialista por excelência, tentar explicar o problema da pessoa a partir de um ponto de vista nitidamente existencial. ${ }^{61}$ Não nega, com isto, a definição de Boécio, que toma como pressuposto para a sua, mas a completa e dá-lhe um outro cunho, substituindo o esquema lógico-categorial pelo existencial. Pessoa, diz ele, não é um quid, mas um quem, não é um algo, mas um alguém. A pessoa é sempre um sujeito com existência extramental. A substância indivídua de natureza intelectual só se torna pessoa quando recebe aquele algo a mais da existência. Contudo, se o individuo se constitui por uma entidade positiva, a pessoa, ao contrário, não possui uma realidade positiva a constituí-la. Não existe nada de comum, que possa ser dito in quid, a partir dos elementos distintivos e constitutivos últimos das pessoas, porque a este nível eles são primeiramente diversos. Tem-se então um conceito negativo, dizendo que o que existe de comum não é o que as

M. McC. Adams. loc. cit. p. 854.

37 "Persona est naturae rationalis substantia individua" (De persona et duabus naturis, c 3; PL 64, 1343),

Ord. I, d 23, q un., n 15-25; V, 355-363.

"Intellectualis naturae incommunicabilis exsistentia" (IV De Trinitate, c 21; PL 196, 945s).

E. Rivera de Ventosa. "Doble plano metafísico de la persona en la Filosofía de Duns Escoto y su interpretación en el pensamiento actual". In: Deus et homo..., p. 294.

62

Rep. Par. I, d 25, q 1, n 5; Vivès XXII, 285. 
assemelha, mas o que as distingue: a incomunicabilidade. ${ }^{\infty} \mathrm{O}$ que as pessoas possuem em comum é o não poderem comunicar a 'pessoalidade', é a ultima solitudo, a última solidão. ${ }^{64}$ Última, porque não existe nada por trás da pessoa, ela é tão somente ela, única, irrepetível; solidão, porque a pessoa está entregue totalmente a si. Não só Agostinho, mas também Scotus, sabe que é no mais íntimo de sua interioridade que o homem descobre a si mesmo e, ao mesmo tempo, descobre a solitudo das pessoas divinas e das humanas. E então a solidão transforma-se em solidariedade ou, como diz belamente a língua espanhola, la soledad se transforma en solidariedad.

6. "Dico quod ab ultimis distinctivis et constitutivis personarum nihil potest abstrahi commune dictum de eis in 'quid', quia illa sunt primo diversa, hoc est nihil idem realiter includentia (tunc enim esset quaerere de eis per quid distinguerentur); et ideo omne commune abstractum ab eis vel est conceptus omnino negativus, vel saltem non est quidditativus conceptus rationis. [...] Quibuscumque ergo repugnat affirmatio unius rationis, eis convenit negatio unius rationis. [...] Si illa dicatur esse incommunicabilitas, et si ponatur incommunicabilitatem solam esse de per se ratione constitutiva personae (ita quod personalitas sit incommunicabilitas subsistentis in natura intellectuali' [...]) tunc persona proprie non dicet aliquem conceptum positivum proprie [...]" (Ord. I, d 23, q un., n 20; V, 360).

64 "Ad personalitatem requiritur ultima solitudo, sive negatio dependentiae actualis et aptudinalis" (Ord. III, d 2, q 1; Vivès XIV, 45). 